Keywords: Macular volume; Optical coherence tomography; Retinal nerve fiber layer thickness; Schizophrenia.

\title{
Retinal nerve fiber layer thickness measured by optical coherence tomography in patients with schizophrenia: A short report
}

\author{
Francisco J. Ascaso ${ }^{\star, \star \star, \star \star \star \star}$ \\ Laura Cabezón* \\ Miguel Ángel Quintanilla**** \\ Leticia Gutiérrez Galve ${ }^{\star \star, \star \star \star}$ \\ Raúl López-Antón ${ }^{\star * * * *}$ \\ José A. Cristóbal ${ }^{\star}$ \\ Antonio Lobo ${ }^{\star \star, * \star * \star, * \star \star \star,, \star * \star \star \star \star}$ \\ * Department of Ophthalmology, \\ Hospital Clínico Universitario, Zaragoza \\ ${ }^{* *}$ Aragon Health Sciences, Institute $(\mathrm{I}+\mathrm{CS})$ \\ *** School of Medicine, University \\ of Zaragoza \\ **** Departament of Psychiatry, Hospital \\ Clínico Universitario, Zaragoza
}

Centro de Investigación Biomédica en

Red de Salud Mental (CIBERSAM), Instituto de Salud Carlos III, Ministerio de Ciencia e Innovación, Madrid

SPAIN

\footnotetext{
ABSTRACT - Background and Objectives: Our study aims to assess retinal nerve fiber layer (RNFL) thickness in patients affected by schizophrenia.

Methods: Ten schizophrenic patients (mean age $39+/-13$ years, best corrected visual acuity $\geq 20 / 20$, refractive error between $+/-2$ diopters, and intraocular pressure $<18$ $\mathrm{mmHg}$ ) were enrolled. They were compared with 10 age-matched controls. In all subjects, optic nerve head $(\mathrm{ONH})$ measurements, peripapillary RNFL thickness, macular thickness and volume were measured by optical coherence tomography (OCT).

Results: Schizophrenic patients showed an statistically significant reduction of the overall RNFL thickness (95+/-13 $\mu \mathrm{m}$, range: 53-110) compared with those values observed in control eyes $(103+/-8 \mu \mathrm{m}$, range: $88-119)(\mathrm{p}=0.047$, Mann-Whitney U test). We also observed reduced peripapillary RNFL thickness in nasal quadrant in schizophrenic patients $(75+/-17 \mu \mathrm{m}$, range: $41-111)$ when compared with controls $(84+/-10 \mu \mathrm{m}$, range: 67-105) ( $\mathrm{p}=0.048$, Mann-Whitney $\mathrm{U}$ test). The remaining peripapillary RNFL quadrants, macular thickness and volume did not reveal differences between both groups. No statisti-
} 
cally significant differences were observed between the control group and schizophrenia patients with regard to $\mathrm{ONH}$ measurements, macular thickness and volume.

Conclusions: Schizophrenia patients had a reduction of peripapillary RNFL thickness evaluated by OCT. To our knowledge, neither reduced RNFL thickness nor macular thickness and volume have been previously documented in patients diagnosed with schizophrenia. These findings suggest that neuronal degeneration could be present in the retina of schizophrenic patients as previously observed in neurodegenerative disorders.

Received: 24 October 2010

Revised: 18 November 2010

Accepted: 20 November 2010

\section{Introduction}

Schizophrenia is a disabling mental condition that affects over 2 million people in the USA alone, but its etiology remains poorly understood ${ }^{1,2}$. Researchers for the past 30 years have looked for specific brain structural abnormalities in this disease ${ }^{3}$. Firstly, the disorder was studied by examining pathological brain tissue samples, often derived from patients who had died after a prolonged period of illness. In recent years, with the advent of brain imaging methods such as magnetic resonance imaging (MRI), it has become possible to study brain structure in individuals during their first episode of psychosis. Findings of several neuroimaging studies have included ventricular enlargement (particularly lateral ventricles), total brain volume deficits, and reductions in the volumes of thalamus, hippocampus, anterior cingulate cortex, and in the area of the corpus callosum ${ }^{4-14}$. However, there is still uncertainty about the key areas involved in the pathogenesis of this condition ${ }^{15}$.

Optical coherence tomography (OCT) is a relatively new noninvasive imaging technique that can assess the thickness of retinal nerve fiber layer (RNFL), macular thickness and volume, and is used in various ophthalmologic disorders including glaucoma ${ }^{16}$ and macular diseases ${ }^{17}$. A decreased thickness can correspond to neuronal death and axonal loss in RNFL. In earlier reports, RNFL thickness was assessed in normal individuals and the results showed that gender has no effect on the evaluation, whereas aging can be associated with a reduction of RNFL thickness ${ }^{18-20}$. Using OCT, a significant reduction in the peripapillary RNFL thickness has been reported in patients with various neurologic diseases ${ }^{21}$, such as multiple sclerosis ${ }^{22-33}$, Alzheimer's disease ${ }^{34-37}$ and Parkinson's disease, suggesting that this technology might also prove useful in other neurodegenerative disorders ${ }^{38-40}$.

The goals of this study were to determine by OCT the differences in the peripapillary RNFL thickness, macular thickness and volume, between schizophrenic patients and control subjects, and to assess whether a correlation exists between the RNFL thickness and the clinical severity of the disease.

\section{Material and methods}

We compared 20 eyes of ten patients ( 8 males and 2 females) with schizophrenia to 20 eyes from ten age-matched healthy control subjects ( 8 males and 2 females). The 
schizophrenic patients were consecutively obtained from the Department of Psychiatry at the Hospital Clínico Universitario in $\mathrm{Za}-$ ragoza, Spain. The patients underwent a detailed psychiatric examination including a semi structured clinical interview following the SCID outline and all them fulfilled the inclusion and exclusion DSM-IV-TR criteria of schizophrenia. They were also assessed by means of the PANSS interview. The control subjects were recruited from the Department of Ophthalmology of the same hospital. After appropriate information, written informed consent of all subjects was obtained. The research followed the tenets of the Declaration of Helsinki, and the protocol was approved by the local ethics committee. The control subjects also underwent a detailed neurological examination. All schizophrenic patients and control subjects underwent a complete ophthalmologic examination, including assessment of best-corrected visual acuity, ocular motility, pupillary reflexes, slit lamp biomicroscopy, intraocular pressure (IOP) measurement, and dilated fundus examination. The examiners were not masked to the diagnosis. All participants had a corrected visual acuity of 20/20 or better with a refractive error between \pm 2 spheric diopters, and IOP less than $18 \mathrm{mmHg}$. Eyes with posterior pole pathology such as macular degeneration or diabetic retinopathy, glaucoma suspect, or patients with media opacification such as cataract or vitreous hemorrhage that prevented ocular and OCT examination were excluded.

Neuropsychological examinations and OCT were performed on the same day. OCT was performed with the Stratus OCT (Carl Zeiss Meditec Inc., Dublin, CA, USA) following dilation of the pupils with $1 \%$ tropicamide. Only high-quality images (signal strength $\geq 7$ ) were included. Each patient underwent scans to measure RNFL thick- ness, optic nerve head (ONH) parameters, and macular thickness at the same visit. RNFL thickness was automatically calculated by the fast RNFL algorithm. Three $360^{\circ}$ circular scans with a diameter of $3.4 \mathrm{~mm}$ centered on the optic disc were performed. The software allows the mapping of the thickness data according to both quadrantby-quadrant and a clock hour analyses. We considered the average values of three different measurements per quadrant (superior, inferior, nasal and temporal): the overall data obtained in all quadrants were identified as overall RNFL thickness. Optic nerve head $(\mathrm{ONH})$ measurements were obtained by the fast optical disk scanning protocol, which consists of six radial scans in a spoke-like pattern centered on the $\mathrm{ONH}$. ONH parameters were automatically calculated, including cup/disc area ratio, horizontal cup/ disc ratio, and vertical cup/disc ratio. Macular thickness measurements were obtained by the fast macular thickness protocol, which consists of six radial scans (each $6 \mathrm{~mm}$ ) in a spoke-like pattern centered on the fovea, with each radial scan spaced $30^{\circ}$ apart. To fill the gaps between scans, the OCT uses interpolation. Stratus OCT software calculates retinal thickness as the distance between the first signal from the vitreoretinal interface and the signal from the anterior boundary of the retinal pigment epithelium. The map is composed of nine sectorial thickness measurements in three concentric circles with diameters of $1 \mathrm{~mm}, 3$ $\mathrm{mm}$, and $6 \mathrm{~mm}$. The area bounded by the outer $(6-\mathrm{mm})$ and middle $(3-\mathrm{mm})$ circles forms the outer ring, and the area bounded by the middle (3-mm) and inner circles (1$\mathrm{mm}$ ) forms the inner ring. The central 1-mm circular region represents the foveal area. Total average macular thickness, average macular thicknesses in the inner (1-3 mm) and outer (3-6 $\mathrm{mm})$ rings, and the central 1$\mathrm{mm}$ fovea thickness were analyzed in the 
study. Total macular volume was calculated automatically by the OCT software.

Data analysis was conducted using SPSS software version 15.0 (SPSS, Inc, Chicago, IL, USA). Values were presented as mean \pm standard deviation (SD) and expressed in microns $(\mu \mathrm{m})$ for the peripapillary RNFL thickness and macular retinal thickness, and in $\mathrm{mm}^{3}$ for macular volume. The two-sample Mann-Whitney U test for nonparametric numbers was used for determining whether the values of a particular variable differ between schizophrenia and control eyes. A p value < 0.05 was considered statistically significant.

\section{Results}

Demographic characteristics of control subjects and schizophrenia patients are shown in Table 1. Not statistically significant differences of mean age were observed between groups ( $\mathrm{p}=0.913$, Mann-Whitney $\mathrm{U}$ test). In both groups, more men than women were enrolled. Although the difference was statistically significant $(p<0.05$; chi-square test), gender has no effect on RNFL evaluation as previously mentioned. Best-corrected visual acuity was similar in both groups. Optic nerve head (ONH) analysis results were also similar in both groups (Table 2). Table 3 shows the mean data and statistical results of peripapillary RNFL thickness in both groups. Overall RNFL thickness was within 88 and $119 \mu \mathrm{m}$ (mean \pm SD: $103 \pm 8 \mu \mathrm{m}$ ) in control subjects and within 53 and $110 \mu$ m (mean \pm SD: $95 \pm$ $13 \mu \mathrm{m})$ in schizophrenia patients. The difference was statistically significant ( $\mathrm{p}=$ 0.047, Mann-Whitney U test). Only the nasal quadrant of peripapillary RNFL showed an statistically significant reduced thickness in schizophrenia patients, compared with that of control subjects. Mean values of macular thickness and volume in control subjects and schizophrenia patiens are shown in Table 4. No statistically significant differences were observed between control group and schizophrenia patients with regard to the average foveal (1-mm) thickness $(\mathrm{p}=$ $0.839)$, average inner ring macular thickness $(\mathrm{p}=0.685)$, average outer macular macular thickness $(\mathrm{p}=0.273)$, or macular volume $(\mathrm{p}=0.705)$ (Mann-Whitney U test).

Table 1

Demographic data in control subjects and schizophrenia patients

Gender (male/female)

$8 / 2$

$8 / 2$

Schizophrenia patients $(\mathrm{n}=10)$

Control subjects $(n=10)$$$
\text { Schizophrenia patients (n = 10) }
$$

p value
${ }^{\mathrm{a}}$ chi-square test.
${ }^{\mathrm{b}}$ Mann-Whitney U test.

[24-64]

Age (years)

Mean \pm SD

[Range]

$39.5 \pm 13.6$

$39.2 \pm 13.5$

[50-88]

$0.913^{b}$


Table 2

Mean values \pm standard deviation of optic nerve head parameters in control subjects and schizophrenia patients

$$
\mathrm{C} / \mathrm{D} \mathrm{R} \quad \mathrm{C} / \mathrm{D} \mathrm{H} \quad \mathrm{C} / \mathrm{D} \mathrm{V}
$$

\begin{tabular}{lccc}
\hline Control eyes $(\mathrm{n}=20)$ & $0.29 \pm 0.26$ & $0.29 \pm 0.20$ & $0.48 \pm 0.21$ \\
\hline Schizophrenia eyes $(\mathrm{n}=20)$ & $0.39 \pm 0.33$ & $0.61 \pm 0.24$ & $0.54 \pm 0.26$ \\
\hline *p value & 0.291 & 0.198 & 0.481
\end{tabular}

* Mann-Whitney U test.

C/D R: cup/disc area ratio; C/D H: horizontal cup/disc ratio; C/D V: vertical cup/disc ratio.

Table 3

Comparison of peripapillary RNFL thickness $(\mu \mathrm{m})$, overall and in the different quadrants, in control eyes and in eyes of schizophrenia patients

\begin{tabular}{lccccc} 
& $\begin{array}{c}\text { Overall } \\
{[\text { Range }]}\end{array}$ & $\begin{array}{c}\text { Superior } \\
{[\text { Range] }}\end{array}$ & $\begin{array}{c}\text { Inferior } \\
{[\text { Range }]}\end{array}$ & $\begin{array}{c}\text { Nasal } \\
{[\text { Range }]}\end{array}$ & $\begin{array}{c}\text { Temporal } \\
{[\text { Range] }}\end{array}$ \\
\hline $\begin{array}{l}\text { Control eyes } \\
\text { Mean } \pm \text { SD } \\
(\mathrm{n}=20)\end{array}$ & $103 \pm 8$ & $127 \pm 12$ & $128 \pm 20$ & $84 \pm 10$ & $76 \pm 10$ \\
\hline $88-119]$ & {$[106-155]$} & {$[93-171]$} & {$[67-105]$} & {$[61-88]$} \\
\hline $\begin{array}{l}\text { Schizophrenia eyes } \\
\text { Mean } \pm \text { SD } \\
(\mathrm{n}=20)\end{array}$ & $95 \pm 13$ & $119 \pm 17$ & $116 \pm 21$ & $75 \pm 17$ & $70 \pm 15$ \\
${ }^{* p}$ value & {$[53-110]$} & {$[80-143]$} & {$[40-141]$} & {$[41-111]$} & {$[26-91]$} \\
\hline
\end{tabular}

* Mann-Whitney U test.

Table 4

Mean values \pm standard deviation of macular thickness and macular volume measurements in control subjects and schizophrenia patients

\begin{tabular}{lcccc} 
& $\begin{array}{c}\text { Outer ring } \\
{[\text { Range] }}\end{array}$ & $\begin{array}{c}\text { Inner ring } \\
{[\text { Range] }}\end{array}$ & $\begin{array}{c}\text { Foveal } \\
{[\text { Range] }}\end{array}$ & $\begin{array}{c}\text { Macular volume } \\
{[\text { Range] }}\end{array}$ \\
\hline Control eyes & $236 \pm 13$ & $270 \pm 11$ & $199 \pm 20$ & $6.9 \pm 0.3$ \\
$\begin{array}{l}\text { Mean } \pm \text { SD } \\
(\mathrm{n}=20)\end{array}$ & {$[218-263]$} & {$[251-299]$} & {$[171-253]$} & {$[6.4-7.5]$} \\
\hline $\begin{array}{l}\text { Schizophrenia eyes } \\
\text { Mean } \pm \text { SD } \\
(\mathrm{n}=20)\end{array}$ & $241 \pm 18$ & $268 \pm 18$ & $197 \pm 18$ & $6.9 \pm 0.4$ \\
*p value & {$[201-272]$} & {$[228-299]$} & {$[175-241]$} & {$[5.9-7.7]$} \\
\hline
\end{tabular}

* Mann-Whitney U test. 


\section{Discussion}

Schizophrenia is thought to be a mental disorder caused by the disconnection of brain regions ${ }^{41,42}$. The most evident focal brain abnormalities in schizophrenic patients are those of grey matter volume loss and ventricular volume increase, and these findings might be related ${ }^{43}$. This knowledge comes from critical advances in imaging technology -including structural (CT, MRI), and functional neuroimaging (PET) methods- all of which provide an unprecedented view of neuroanatomical structures, in vi$\mathrm{vo}^{41,44,45}$. Nevertheless, there are many difficulties in measuring brain volumes of patients with schizophrenia by MRI. An enormous problem is that the volumetric loss in patients is less than $4 \%$ per year, which may be close to the limit of detection by MRI, given the precision of volumetric methods $^{46,47}$. Another major problem is that we do not kwow the effects of antipsychotic medications on total brain volume ${ }^{48-50}$. A further difficulty inherent to studying firstepisode cases is that some patients may have been symptomatic, but undiagnosed, for a long time. If progressive brain volume changes are rapid in the period surrounding diagnosis, then the duration of undiagnosed illness would be a serious confounder. However, since no consistent relationship has been found between duration of illness and brain volume loss, this may be less likely ${ }^{51}$.

OCT measurements are of particular interest in numerous neurologic diseases in which there is axonal loss ${ }^{21}$. Several studies have demonstrated evidence of RNFL thinning in various neurologic disorders, such as multiple sclerosis ${ }^{22-33,52}$, Alzheimer's disease $^{34-37}$ and Parkinson's disease, suggesting that this technology might also prove useful in other neurodegenerative disorders $^{38-40}$. To the best of our knowledge, this is the first report to demonstrate a thin- ner overall peripapillary RNFL thickness in schizophrenia patients when compared with controls. Moreover, we observed that the thinning of the peripapillary RNFL was most pronounced in the nasal quadrant.

An age-related reduction of RNFL thickness in normal subjects has been reported ${ }^{53}$. However, the reduction in RNFL thickness observed in our schizophrenic patients was significantly greater than that observed in the age-matched controls and, therefore, it cannot be exclusively ascribed to aging.

RNFL includes retinal ganglion neurons and their axons which form the origin of the optic nerve. The loss of retinal ganglion cells and their fibers observed in schizophrenic patients could be ascribed to a neurodegenerative process involving neuroretinal structures. However, more studies are needed to give further explanations about the relationship between the pathological mechanisms underlying schizophrenia and the reduction in peripapillary RNFL thickness we have observed.

It remains to be determined whether schizophrenia is a neurodegenerative process that begins at about the time of symptom onset and manifests as progressive volumetric loss thereafter, or whether it is better characterized as a neurodevelopmental process that results in abnormal brain volume beginning at an early age ${ }^{54}$.

\section{References}

1. Steen RG, Mull C, McClure R, Hamer RM, Lieberman JA. Systematic review and meta-analyisis of magnetic resonance imaging studies. Br J Psychiatry 2006; 188: 510-518.

2. Siever LJ, Davis KL. The pathophysiology of schizophrenia disorders: perspectives from the spectrum. Am J Psychiatry 2004; 161: 398-413. 
3. Honea R, Crow TJ, Passingham D, Mackay CE. Regional deficits in brain volume in schizophrenia: a metaanalysis of voxel-based morphometry studies. Am J Psychiatry 2005 ; 162: 2233-2245.

4. Nelson MD, Saykin AJ, Flashman LA, Riordan HJ. Hippocampal volume reduction in schizophrenia as assessed by magnetic resonance imaging: a meta-analytic study. Arch Gen Psychiatry 1998; 55: 433-440.

5. Konick LC, Friedman L. Meta-analysis of thalamic size in schizophrenia. Biol Psychiatr 2001; 49: 28-38.

6. Baiano M, David A, Versace A, Churchill R, Balestrieri M, Brambilla P. Anterior cingulate volumes in schizophrenia: a systematic review and a meta-analysis of MRI studies. Schizophr Res 2007; 93: 1-12.

7. Woodruff PW, McManus IC, David AS. Meta-analysis of corpus callosum in schizophrenia. J Neurol Neurosurg Psychiatry 1995; 58: 457-461.

8. Arnone D, Mcintosh AM, Tan GMY, Ebmeier KP. Meta-analysis of magnetic resonance imaging studies of the corpus callosum in schizophrenia. Schizophr Res 2008; 101: 124-132.

9. Wright IC, Rabe-Hesketh S, Woodruff PW, David AS, Murray RM, Bullmore ET. Meta-analysis of regional brain volumes in schizophrenia. Am J Psychiatry 2000; 157: 16-25.

10. Ellison-Wright I, Glahn DC, Laird AR, Thelen SM, Bullmore E. The anatomy of first-episode and chronic schizophrenia: an anatomical likelihood estimation metaanalysis. Am J Psychiatry 2008; 165: 1015-1023.

11. Shenton ME, Dickey CC, Frumin M, McCarley RW. A review of MRI findings in schizophrenia. Schizophr Res 2001; 49: 1-52.

12. Lawrie SM, Abukmeil SS. Brain abnormality in schizophrenia: a systematic and quantitative review of volumetric magnetic resonance imaging studies. Br J Psychiatry 1998; 172: 110-120.

13. McCarley RW, Wible CG, Frumin M, Hirayasu Y, Levitt JJ, Fischer IA, et al. MRI anatomy of schizophrenia. Biol Psychiatry 1999; 45:1099-1119.

14. Ward KE, Friedman L, Wise A, Schulz SC. Metaanalysis of brain and cranial size in schizophrenia. Schizophr Res 1996; 22: 197-213.

15. Arnone D, Cavanagh J, Gerber D, Lawrie SM, Ebmeier KP, Mcintosh AM. Magnetic resonance imaging studies in bipolar and schizophrenia: meta-analysis. Br J Psychiatry 2009; 195: 194-201.
16. Jaffe GJ, Caprioli J. Optical coherence tomography to detect and manage retinal disease and glaucoma. Am J Ophthalmol 2004; 137: 156-169.

17. Hassenstein A, Spital G, Scholz F, Henschel A, Richard G, Pauleikhoff D. Optical coherence tomography for macula diagnostics. Review of methods and standardized application concentrating on diagnostic and therapy control of age-related macula degeneration. Ophthalmologe 2009; 106: 116-126.

18. Bowd C, Zangwill LM, Blumenthal EZ, Vasile C, Boehm AG, Gokhale PA, et al. Imaging of the optic disc and retinal nerve fiber layer: effects of age, optic disc area, refractive error and gender. J Opt Soc Am A Opt Image Sci Vis 2002; 19: 197-207.

19. Kanamori A, Escano M-F, Eno A, Nakamura M, Maeda H, Seya R, et al. Evaluation of the effect of aging on retinal nerve fiber layer thickness measured by optical coherence tomography. Ophthalmologica 2003; 217: 273-278.

20. Varma R, Bazzaz S, Iai M. Optical tomographymeasured retinal nerve fiber layer thickness in normal latinos. Invest Ophthalmol Vis Sci 2003; 44: 3369-3373.

21. Lamirel C, Newman N, Biousse V. The use of optical coherence tomography in Neurology. Rev Neurol Dis 2009; 6(4): E105-E120.

22. Sergott RC, Frohman E, Glanzman R, Al-Sabbagh A. The role of optical coherence tomography in multiple sclerosis: expert panel consensus. J Neurol Sci 2007;263: 3-14.

23. Frohman EM, Fujimoto JG, Frohman TC, Calabresi PA, Cutter G, Balcer LJ. Optical coherence tomography: a window into the mechanisms of multiple sclerosis. Nat Clin Pract Neurol 2008; 4: 664-675.

24. Parisi V, Manni G, Spadaro M, Colacino G, Restuccia R, Marchi S, et al. Correlation between morphological and functional retinal impairment in multiple sclerosis patients. Invest Ophthalmol Vis Sci 1999; 40: 2520-2527.

25. Fisher JB, Jacobs DA, Markowitz CE, Galetta SL, Volpe NJ, Nano-Schiavi ML, et al. Relation of visual function to retinal nerve fiber layer thickness in multiple sclerosis. Ophthalmology 2006; 113: 324-332.

26. Sepulcre J, Murie-Fernandez M, Salinas-Alaman A, García-Layana A, Bejarano B, Villoslada P. Diagnostic accuracy of retinal abnormalities in predicting disease activity in MS. Neurology 2007; 68: 1488-1494.

27. Henderson AP, Trip SA, Schlottmann PG, Altmann DR, Garway-Heath DF, Plant GT, et al. An investigation of the retinal nerve fibre layer in progressive multiple sclerosis using optical coherence tomography. Brain 2008; 131: 277-287. 
28. Narayanan S, Fu L, Pioro E, De Stefano N, Collins DL, Francis GS, et al. Imaging of axonal damage in multiple sclerosis: spatial distribution of magnetic resonance imaging lesions. Ann Neurol 1997; 41: 385-391.

29. De Stefano N, Matthews PM, Fu L, Narayanan S, Stanley J, Francis GS, et al. Axonal damage correlates with disability in patients with relapsing-remitting multiple sclerosis. Results of a longitudinal magnetic resonance spectroscopy study. Brain 1998; 121: 1469-1477.

30. Thrower BW. Clinically isolated syndromes: predicting and delaying multiple sclerosis. Neurology 2007; 68: S12-S15.

31. Frisen L, Hoyt WF. Insidious atrophy of retinal nerve fibers in multiple sclerosis. Funduscopic identification in patients with and without visual complaints. Arch Ophthalmol 1974; 92: 91-97.

32. Ikuta F, Zimmerman HM. Distribution of plaques in seventy autopsy cases of multiple sclerosis in the United States. Neurology 1976; 26: 26-28.

33. Toussaint D, Perier O, Verstappen A, Bervoets S. Clinicopathological study of the visual pathways, eyes, and cerebral hemispheres in 32 cases of disseminated sclerosis. J Clin Neuroophthalmol 1983; 3: 211-220.

34. Parisi V, Restuccia R, Fattapposta F, Mina C, Bucci MG, Pierelli F. Morphological and functional retinal impairment in Alzheimer's disease patients. Clin Neurophysiol 2001; 112: 1860-1867.

35. Iseri PK, Altinas O, Tokay T, Yuksel N. Relationship between cognitive impairment and retinal morphological and visual functional abnormalities in Alzheimer disease. $\mathrm{J}$ Neuroophthalmol 2006; 26: 18-24.

36. Paquet C, Boissonnot M, Roger F, Dighiero P, Gil R, Hugon J. Abnormal retinal thickness in patients with mild cognitive impairment and Alzheimer's disease. Neurosci Lett 2007; 420: 97-99.

37. Berisha F, Feke GT, Trempe CL, McMeel JW, Schepens CL. Retinal abnormalities in early Alzheimer's disease. Invest Ophthalmol Vis Sci 2007; 48: 2285-2289.

38. Inzelberg R, Ramirez JA, Nisipeanu P, Ophir A. Retinal nerve fiber layer thinning in Parkinson disease. Vision Res 2004; 44: 2793-2797.

39. Altintas O, Iseri P, Ozkan B, Caglar Y. Correlation between retinal morphological and functional findings and clinical severity in Parkinson's disease. Doc Ophthalmol 2008; 116: 137-146.

40. Hajee ME, March WF, Lazzaro DR, Wolintz AH, Shrier EM, Glazman S, et al. Inner retinal layer thinning in Parkinson disease. Arch Ophthalmol 2009; 127: 737-741.
41. Shenton ME, Whitford TJ, Kubicki M. Structural neuroimaging in schizophrenia: from methods to insights to treatments. Dialogues Clin Neurosci 2010; 12: 317-332.

42. Di X, Chan RC, Gong QY. White matter reduction in patients with schizophrenia as revealed by voxel-based morphometry: an activation likelihood estimation metaanalysis. Prog Neuropsychopharmacol Biol Psychiatry 2009; 33: 1390-1394.

43. Suddath RL, Casanova MF, Goldberg TE, Daniel DG, Kelsoe JR Jr, Weinberger DR. Temporal lobe pathology in schizophrenia: a quantitativemagnetic resonance imaging study. Am J Psychiatry 1989; 146: 464-472.

44. Davidson LL, Heinrichs RW. Quantification of frontal and temporal lobe brain-imaging findings in schizophrenia: a meta-analysis. Psychiatry Res 2003; 122: 69-87.

45. Zakzanis KK, Heinrichs RW. Schizophrenia and the frontal brain: a quantitative review. J Int Neuropsychol Soc 1999; 5: 556-566.

46. Howard MA, Roberts N, García-Fiñana M, Cowell PE. Volume estimation of prefrontal cortical subfields using MRI and stereology. Brain Res Brain Res Protoc 2003; 10(3): 125-138.

47. MacFall JR, Payne ME, Krishnan KRR. MR scanner geometry changes: phantom measurements compared to intracranial contents calculations. Proceedings of the International Society for Magnetic Resonance in Medicine 2004; 11: 2182.

48. DeLisi LE, Hoff AL, Schwart JE, Shields GW, Halthore SN, Gupta SM, et al. Brainmorphology in firstepisode schizophrenic-like psychotic patients: a quantitativemagnetic resonance imaging study. Biol Psychiatry 1991; 29: 159-175.

49. Chakos MH, Lieberman JA, Bilder RM, Borenstein M, Lerner G, Bogerts B, et al. Increase in caudate nuclei volumes of first-episode schizophrenic patients taking antipsychotic drugs. Am J Psychiatry 1994; 151:1430-1436.

50. Gur RE, Cowell P, Turetsky BI, Gallacher F, Cannon T, Bilker W, et al. A follow-up magnetic resonance imaging study of schizophrenia. Relationship of neuroanatomical changes to clinical and neurobehavioral measures. Arch Gen Psychiatry 1998; 55(2):145-152.

51. Harrison PJ, Freemantle N, Geddes JR. Meta-analysis of brainweight in schizophrenia. Schizophr Res 2003; 64: 25-34.

52. Frohman EM, Fujimoto JG, Frohman TC, Calabresi PA, Cutter G, Balcer LJ. Optical coherence tomography: a window into the mechanisms of multiple sclerosis. Nat Clin Pract Neurol 2008; 4: 664-675. 
53. Gramer E, Dirmeyer M. Optical coherence tomography (OCT) to measure nerve fiber layer thickness in normal eyes. Invest Ophthalmol Vis Sci 1998; 39(4): S933 (ARVO abstract no. 4296).

54. Maynard TM, Sikich L, Lieberman JA, LaMantia AS. Neural development, cell-cell signaling, and the 'twohit' hypothesis of schizophrenia. Schizophr Bull 2001; 27: 457-476.
Address for correspondence:

Francisco J. Ascaso, MD,

Department of Ophthalmology,

"Lozano Blesa" University Clinic Hospital, San Juan Bosco 15,

ES-50009 Zaragoza, Spain.

Phone: + 34686574389

Fax: + 34976565995

E-mail: jascaso@gmail.com 